\title{
ARTE NO COMBATE À VIOLÊNCIA: EXPERIÊNCIAS ARTÍSTICAS E CULTURAIS NO DESENVOLVIMENTO DO POTENCIAL CRIATIVO- POLÍTICO
}

\author{
Beatriz Skitnevsky (Psicologia - UEL) \\ Profa. Alejandra Astrid Leõn Cedeño (Orientadora)
}

\section{RESUMO}

A partir de um cenário de aumento constante dos índices de violência e alastramento da quantidade de vítimas crianças e jovens, há um início de trabalho a respeito da formulação e efetivação de políticas públicas na perspectiva da prevenção da violência. Contudo, este trabalho é ainda incipiente e durante anos o acesso aos direitos, tais como cultura, esporte e lazer têm sido restritos a uma pequena parcela da população. Por tal motivo, iniciativas autônomas e horizontais têm surgido no sentido de universalizar o acesso à arte e à cultura no combate e prevenção da violência. Em Londrina/PR, dois exemplos desse tipo de iniciativas, o Ciranda e o $\mathrm{MH} 2$ - música e hip-hop, partem originalmente de propostas de moradores de bairros periféricos da cidade para atender outros moradores dessas regiões. O presente artigo apresenta uma pesquisa que busca entender a capacidade de desenvolvimento do potencial criativo-político dos indivíduos que delas participam com vistas a transformação da realidade vigente e da possível prevenção da violência.

Palavras-chave: Potencial criativo-político, Arte, Cultura, Prevenção da violência.

\section{INTRODUÇÃO}

Nosso exercito está fortemente armado/Atirando poesia, crônica, rima/É verso pra todos os lados/

Sua educação privada/Não vai nos tirar mais nada/Pois todo o dia surge mais um sarau na quebrada!

E aí, já deu pra entender? /Isso aqui é revolução:/Preto, poeta e periférico/Muito Prazer, /Eu sou a contra indicação.

(Cleyton Meneses, vencedor do Slam Tagarela.)

A pesquisa aqui apresentada se trata de um estudo que acompanha potentes experiências em iniciativas que combinam arte, cultura e resistência política, evidenciando o potencial de transformação social que tais iniciativas podem construir ou influenciar, superando, reduzindo e/ou invalidando os efeitos da violência. O que se dá a partir da viabilização da agência do indivíduo na realidade em que está inserido, criando novas possibilidades à sua existência e à existência coletiva dos indivíduos que compartilham realidades afins à sua.

No continente Americano parece haver uma miríade de iniciativas artísticas que transformaram a sociedade por meio da arte. Um exemplo importante a esse respeito é o caso da escola Orchard Gardens, localizada em Boston no Estado de 


\section{SEMINÁRIO DE PESQUISA EM CIÊNCIAS HUMANAS - SEPECH \\ Humanidades, Estado e desafios didático-científicos \\ Londrina, 27 a 29 de julho de 2016}

Massachusetts, nos Estados Unidos da América. Tal escola apresentava elevados índices de violência e se encontrava entre as cinco piores do Estado.

Com a implantação de um programa de melhoria do Governo Federal para recuperar instituições de ensino, no ano de 2010, o diretor de Orchard Gardens demitiu grande parte dos funcionários da segurança, contratando, simultaneamente, professores de arte nas modalidades de teatro, dança, artes visuais e música (instrumental e coral). Em dois anos da implementação de tal medida, a escola teve os índices de violência diminuídos drasticamente e passou a ser avaliada entre as melhores escolas do Estado, demonstrando a arte como um potencial político de combate à violência (HYPENESS, 2013).

Ao falar de violência no Brasil, deve-se considerar que esta vem se intensificando e compondo a atual conjuntura do cotidiano de suas cidades e que as maiores vítimas são jovens e adolescentes. Segundo o Mapa da Violência 2015 (SECRETARIA NACIONAL DA JUVENTUDE), se comparadas as vítimas de arma de fogo entre os anos de 1980 e 2012, os homicídios aumentaram em 387\%, sendo que os assassinatos de jovens tiveram um aumento em 463,6\%. Além das vítimas fatais, crianças e adolescentes das regiões periféricas são bastante afetadas pelo contexto violento ao qual são submetidas, pois enfrentam diversos problemas em virtude da exposição, espontânea e constante, ao contato com o cenário de tráfico e policiais fortemente armados.

As ocorrências citadas acima se dão em paralelo à imposição de um modo de vida com raras oportunidades para o desenvolvimento das potencialidades humanas, o que corresponde a poucas ou inexistentes creches e escolas, escassas áreas de lazer ou convívio comunitário, restrições no atendimento à saúde, menor qualidade na infraestrutura dos bairros, bem como escassas oportunidades de envolvimento artístico e contato com conteúdo e experiências lúdicas.

O maior bairro da cidade de Londrina (PR), por exemplo, constitui um complexo de moradias populares do programa Minha casa Minha Vida do Governo Federal, onde faltam escolas, mercados, farmácias, postos médicos e qualquer forma de lazer ou convivência. Estes dados indicam indiretamente que, aos olhos do governo, existe uma diferenciação da compreensão das necessidades básicas das populações dependendo das classes sociais em que elas se encontram, pois, segundo Maria Nilza de Silva (2013, p. 8), tais escassezes não se fazem presentes em bairros onde habitam pessoas da classe média/alta.

Em relação à violência que perpassa o cotidiano dessas regiões desprivilegiadas, esta pesquisa considera-se a realização de atividades artísticas e culturais, autônomas e autogeridas, como potentes alternativas aos conflitos permanentes e cotidianos. Iniciativas que, como catalizadoras do desenvolvimento do potencial criativo-político do sujeito, apresentam-se como transformadoras da sociedade.

Para tratar da ação cultural como possibilidade da superação da situação de opressão às quais certas populações são submetidas, Paulo Freire (1981, p. 31), no texto Ação Cultural para a Liberdade, discorre sobre a possibilidade de a transformação da estrutura social depender da ação dos sujeitos pertencentes às classes oprimidas de se conscientizarem sobre os mecanismos de poder que os limitam e os marginalizam.

Assim, a ação cultural demonstra ser um importante veículo de ação para a transformação da sociedade, visto que possibilita a fomentação de uma nova realidade 


\section{SEMINÁRIO DE PESQUISA EM CIÊNCIAS HUMANAS - SEPECH \\ Humanidades, Estado e desafios didático-científicos \\ Londrina, 27 a 29 de julho de 2016}

social à medida que os sujeitos identificam-se como capazes de superar as opressões às quais estão submetidos, como propõe Paulo Freire:

"É algo importante perceber que a realidade social é transformável; que feita pelos homens, pelos homens pode ser mudada; que não é algo intocável, um fado, uma sina, diante de que só houvesse um caminho: a acomodação a ela. É algo importante que a percepção ingênua da realidade vá cedendo seu lugar a uma percepção que é capaz de perceber-se; que o fatalismo vá sendo substituído por uma crítica esperança que pode mover os indivíduos a uma cada vez mais concreta ação em favor da mudança radical da sociedade." (FREIRE, 1981, p.33)

Essa superação das opressões, portanto, se dá no ato de questionar a realidade social como definitiva e intocável, consequência da implicação do sujeito na construção de novas trajetórias subjetivas para sua vida.

O potencial criativo-político ao qual este estudo se refere, segue a perspectiva dos autores Roberto Freire e Fausto Silva (1986), de que a criatividade existe em um sentido propício para que o sujeito desenvolva uma compreensão e ação crítica sobre a sociedade:

\footnotetext{
"Mas, afinal que perigo oferecem a espontaneidade, a originalidade e a criatividade? Lógico, o seu poder de crítica. Quem é espontâneo não sente medo dos outros e critica-os à vontade. Exercendo a sua originalidade, o individuo vai descobrir o que há de falso, anacrônico, impróprio no comportamento das pessoas e nas instituições em que vive. Quando somos criativos, ao mesmo tempo estamos liberando nossa agressividade para transformar, melhorar, revolucionar comportamentos e instituições." (FREIRE, R. e BRITO F., p.47-48, 1984).
}

No sentido de transformar a realidade social regente, na perspectiva aqui adotada, não se faz suficiente apenas apostar no desenvolvimento criativo que iniciativas culturais proporcionam, mas sim no desenvolvimento de um potencial capaz de agir criativamente transformando a realidade com o objetivo da construção de uma sociedade igualitária, horizontal e fraterna, portanto libertária. Sendo assim, diz-se respeito ao desenvolvimento de uma potência criadora e crítica, capaz de produzir o necessário para a transformação. Roberto Freire e Fausto Brito destacam:

“[...] a criatividade é livre, pois, quando o homem usa o seu conhecimento em numerador, ou seja, de forma original e crítica. O que ele produz é assim absolutamente imprevisível, até para si mesmo. Mas certamente, sua obra satisfará carências gerais e exprimirá o necessário, porém inexprimível em todos os outros." (FREIRE, R e BRITO F., p. 47-48, 1984).

Existe também um papel fundamental da arte e do decorrente desenvolvimento do potencial criativo-político que ela proporciona, tal qual é apontado nesta pesquisa. 


\section{SEMINÁRIO DE PESQUISA EM CIÊNCIAS HUMANAS - SEPECH \\ Humanidades, Estado e desafios didático-científicos \\ Londrina, 27 a 29 de julho de 2016}

Quando a cultura e a arte agem instigando o indivíduo a atuar, questionar e criar, notase a potência que fortalece os sujeitos frente aos efeitos da violência e, supõe-se que isto ative possíveis dispositivos no combate e prevenção à violência, bem como dispositivos capazes de colocar o sujeito frente à transformação social.

Iniciativas afins a essa proposta estão espalhadas por todo o Brasil pelos centros urbanos e várias zonas periféricas. Alguns se destacam, como o Sarau da Cooperifa, localizado no Capão Redondo, na cidade de São Paulo, surgida no ano de 2001 e teve como um dos seus principais fundadores o morador da região Sergio Vaz. Esse movimento promove saraus em escolas, bem como em outros espaços públicos desenvolvendo suas atividades há 12 anos, inicialmente em um bar do bairro que virou centro cultural.

Também pode se destacar o Traficante de Livros, localizado na Comunidade do Bode Pina na cidade do Recife, PE. Seu fundador Ricardo Gomes, começou uma biblioteca na sala de sua casa (que antes pertencia a um traficante) e hoje se tornou uma "livroteca".

Outra iniciativa também potente é o movimento Slam poetry, que organiza batalhas de poesia em que o intuito é construir e compartilhar arte e resistência. O Slam acontece em todo o Brasil e também em outros países. Especificamente, em diversos bairros da cidade de São Paulo-SP, ocorrem batalhas de poesia organizadas mensalmente em ruas da cidade e são abertas a todos os públicos. Os conteúdos das poesias compartilhadas, em sua maioria, apresentam conteúdo de resistência política.

$\mathrm{Na}$ cidade de Londrina-PR, encontram-se dois movimentos afins originados da iniciativa de moradores de comunidades localizadas em regiões periféricas com o objetivo de construir coletivamente opções que possibilitem a melhorara do acesso à cultura. A primeira delas é um Centro Cultural chamado Associação Ciranda da Cultura, que funciona de forma diária e gratuita desde 1999. A segunda é o projeto MH2 música e Hip Hop, um projeto financiado pelo PROMIC (Programa Municipal de Incentivo à Cultura) da prefeitura de Londrina, proposto por um rapper e educador no bairro em que ele mora.

Apesar de seguirem a mesma lógica e anseio de proporcionar à comunidade acesso à cultura e à arte, as duas iniciativas estruturam-se de maneiras diferentes. $\mathrm{O}$ "Ciranda", é um Centro Cultural com desenvolvimento de atividades diárias em que o público pode participar ou construir atividades, existindo também uma disposição ao diálogo com políticas públicas, como ocorre com a Unidade Básica de Saúde (UBS) da região e a Universidade Estadual de Londrina - UEL.

Entre os anos de 2015 e 2016, as atividades desenvolvidas semanalmente no espaço do "Ciranda" foram: Cirandinha, Dança para Crianças, Vozes do Ciranda, Brincadeiras, Dança do Ventre, Histórias, Zumba e aulas de alongamento. Exceto a oficina de Zumba, todas as outras atividades são gratuitas e abertas para todos os públicos. Além das oficinas semanais, o "Ciranda" promoveu e se inseriu em movimentações para além de seu espaço físico, como os passeios de oficineiros com as crianças, piqueniques nos parques da cidade, a luta pela permanência de uma escola 


\section{SEMINÁRIO DE PESQUISA EM CIÊNCIAS HUMANAS - SEPECH \\ Humanidades, Estado e desafios didático-científicos \\ Londrina, 27 a 29 de julho de 2016}

municipal no bairro e a construção de um cursinho pré-vestibular comunitário que atende a estudantes da região ${ }^{1}$.

O MH2- música e hip hop é um projeto a fim de universalizar o acesso à cultura e à arte, que busca propagar a cultura do hip hop e aproximar a comunidade à essa cultura de resistência em um cenário de muita escassez de infraestrutura urbana. $\mathrm{O}$ cenário, fruto do programa federal Minha Casa Minha Vida, é um bairro de moradias populares fundado em $2011 \mathrm{em}$ uma antiga área rural da cidade de Londrina (SILVA, 2013, p. 7) com aproximadamente 12 mil habitantes e de acesso aos direitos básicos como saúde e educação precários, quando não, inexistentes, pois não há uma escola ou posto médico no bairro ${ }^{2}$.

Partindo de experiências nessas duas iniciativas igualitárias que não exercem qualquer controle sobre os participantes destas, o "Ciranda" e o Projeto MH2 música e hip hop, o presente trabalho busca apontar o potencial criativo-político desenvolvido por essas atividades no que tange à arte e cultura, a fim de conferir visibilidade a existência de tais projetos fortalecendo uma rede de resistência artística e cultural.

\section{METODOLOGIA}

A pesquisa apresentada se deu durante um ano (entre 2015 e 1016) no âmbito do Curso de Psicologia da Universidade Estadual de Londrina - UEL e tem como base a oficina Vozes do Ciranda, idealizada pela pesquisadora do trabalho ora apresentado, na Associação Ciranda da Cultura e no Projeto MH2 Música e Hip Hop.

No caso do "Ciranda", pesquisa e intervenção ocorreram semanalmente por meio da coordenação da oficina de expressão vocal, denominada Vozes do Ciranda, e mensalmente com a participação em outras atividades promovidos pela da Associação e eventos do bairro, como reuniões e assembleias, festas e comemorações, bem como em movimentações de cunho político da região. A oficina Vozes do Ciranda, também contou com a participação e colaboração de outras oficineiras, estudantes dos cursos de Música, Psicologia e de Ciências Sociais da UEL.

O projeto MH2 Música e Hip Hop tem como proposta oferecer oficinas de música e hip hop gratuitas, semanais - aos sábados, das 16 às 19 horas - e também promover saraus culturais bimestrais nas ruas do bairro (com duração de 5 horas em média). Para a realização deste trabalho, a pesquisadora acompanhou todos os saraus de 2015 e 2016 (até o momento) e compareceu às oficinas uma vez por mês nesse período.

Nessas oficinas discute-se sobre o rap no Brasil e demais estilos musicais, bem como métodos de rimar, ritmar e criar. Já os saraus bimestrais ocorrem em tardes de domingos em uma rua do bairro, ou na quadra de esportes deste, em caso de chuva. Os saraus se diversificam em cada edição, mas a proposta é sempre a de desenvolver atividades culturais que entretenham e engajem os moradores em uma movimentação potentemente transformadora da realidade compartilhada por esses.

\footnotetext{
${ }^{1}$ O cursinho pré-vestibular, denominado Ubuntu, surgido em 2016, é uma construção coletiva e totalmente autônoma, cujas aulas são ministradas por moradoras do bairro e por outros voluntários que oferecem as atividades na escola estadual do bairro.

2 Descrição existente no Plano de Trabalho do projeto destinado ao PROMIC (Programa de Incentivo a Cultura de Londrina) e aprovado pelo mesmo.
} 
Nesta trajetória de contato com o dia-a-dia dessas iniciativas culturais, o trabalho foi permeado pelo marco metodológico da pesquisa no cotidiano (SPINK, 2008, pp. 70-76), entendida sob um olhar psicossocial de transformação ético-política, que sugere ao pesquisador participação e atuação no contexto que está sendo pesquisado. Assim, a pesquisadora exerceu uma contribuição ativa aos dois locais em que pesquisa, seguindo um procedimento de investigação no cotidiano que a Professora Alejandra León Cedeño (2007) denomina como "troca construtiva".

A troca construtiva consiste em um procedimento metodológico propício para o estudo de iniciativas contra hegemônicas, em que a pessoa pesquisadora negocia sua presença no lugar e as condições para que a pesquisa seja satisfatória para os envolvidos e posteriormente vivencia ativamente o cotidiano do coletivo ou agrupamento em questão e, concomitantemente, produz academicamente (CEDEÑO, 2007).

Este procedimento implica em um registro das experiências em diário de campo durante dois meses ou mais (neste caso, por um ano) e, no seguimento de três princípios: ajudar sem atrapalhar, trabalhar por intercâmbio ou troca e ajudar a fortalecer a rede afetiva dos coletivos até onde seus membros o considerarem pertinente, demonstrando como práticas igualitárias tem lugar em iniciativas específicas (CEDEÑO, 2007).

O princípio de ajudar sem atrapalhar, que propõe à pesquisadora uma participação ativa e de contribuição nas atividades sugeridas pelas iniciativas em questão, propicia colocar em prática as suas habilidades ao mesmo tempo em que proporciona o desenvolvimento de novos conhecimentos e novas habilidades, mesmo que tais recursos estejam voltados apenas ao não atrapalhar o funcionamento orgânico do coletivo; o segundo princípio da trabalhar por intercâmbio ou troca implica no oferecimento de compromissos e trocas às iniciativas estudadas, para a realização da pesquisa acadêmica, devolvendo ao coletivo, simultaneamente, os conhecimentos produzidos pela pesquisa; por fim, no que tange ao princípio de ajudar e fortalecer a rede afetiva dos coletivos, é sugerido o estreitamento dos laços afetivos no sentido da emancipação coletiva. Tais pressupostos foram corroborados na realização da pesquisa descrita, nas relações da pesquisadora fortalecendo uma rede libertária de resistência política e cultural.

\section{RESULTADOS E DISCUSSÃO}

Considerando o cotidiano como fonte da emancipação e transformação social, foi possível uma análise dos indícios da fomentação e fortalecimento do potencial criativo-político nas iniciativas em que a pesquisadora esteve inserida.

\subsection{Sobre Vozes do Ciranda}

A oficina Vozes do Ciranda, em que a pesquisadora atuou com os conhecimentos que possui sobre música e expressão vocal, tem um público com média de idade entre 08 e 12 anos. A denominação da oficina surgiu a partir de uma deliberação em uma assembleia da própria oficina no dia 14 de Setembro, de 2015, a partir da compreensão de que as atividades propostas à oficina pelas oficineiras, bem 


\section{SEMINÁRIO DE PESQUISA EM CIÊNCIAS HUMANAS - SEPECH \\ Humanidades, Estado e desafios didático-científicos \\ Londrina, 27 a 29 de julho de 2016}

como as atividades espontâneas que lá surgiam, não se tratavam apenas de exercícios vocais, mas de um trabalho com músicas, ritmos e ideias, tudo ocorrendo em uma relação dialógica com o cotidiano dos cirandeiros ${ }^{3}$.

Trata-se de um espaço de fala, escuta, criação e análise crítica do cotidiano que se identificam como fatores presentes na oficina Vozes do Ciranda. Essas premissas conferem à oficina características mutáveis em função das movimentações e demandas que surgem no âmbito da Associação Ciranda da Cultura, como também fora do local, mas que influenciam suas atividades.

Os objetivos da oficina, objeto deste trabalho, voltam-se com evidência ao empoderamento do sujeito e de suas possibilidades de a criar novas trilhas subjetivas e concretas perante à realidade que perpassa suas vidas. Tais pressupostos partem da existência de uma aposta, portanto, de que a música e a voz ajudam na construção de uma nova postura do sujeito em seu cotidiano, uma postura autônoma.

É notória, nas atividades desenvolvidas na oficina, a existência de um espaço que possibilita convivência solidária através de atividades culturais, capaz de despertar, em algumas ocasiões, uma potente criatividade livre dos métodos de dominação da classe dominante, como no caso marcante da criação do Hino do Ciranda, tal como registrado no Diário de Campo, a saber:

A partir da proposta de criar uma música do Ciranda, pedimos para que as crianças, que desenhassem ou escrevessem qualquer coisa em relação ao Ciranda, para que a partir disso, construíssemos a letra da nossa música. [...] Um dos cirandeiros começou a contar, quase que em tom de declamação de poesia, as diferenças que percebia no Ciranda em relação a sua escola: "Na escola não pode brincar, no Ciranda tem oficina de brincadeira, na escola tem aula de história e é chato, no Ciranda tem contação de histórias, na escola a gente é obrigado a ir, no Ciranda a gente vai porque quer, na escola eles falam não pra tudo e no Ciranda as professoras falam sim".[...] A maior parte das crianças relatou o Ciranda como um espaço pra encontrar amigos e fazer novas amizades e a coordenadora criou o que viria ser o refrão:

"O ciranda é um lugar de encontros, liberdade e sonhos

Onde todos são o que são

Do que acontece no Ciranda, fica alegria e reflexão" (Diário de campo, 9 nov, 2015).

O trabalho exercido na oficina "Vozes do Ciranda" é sobre o conteúdo das coisas que os cirandeiros levam até o Ciranda, inclusive sobre os conteúdos que propaguem alguma forma de violência. Ignorar que as crianças reproduzem mecanismos de poder e de dominação, seria exercer certa ingenuidade, desconsiderando a atuação dos grupos dominantes em defesa de seus interesses (FREIRE, 1981).

Durante as oficinas, procura-se valorizar a cultura popular, assim como se valoriza qualquer indivíduo considerando-se especialmente aqueles que fazem parte de grupos sobre os quais recaem preconceitos e estereótipos: as mulheres, a população negra e a população LGBT, pois, como coloca Freire (1981), essa espécie de trabalho que procura promover a transformação social deve estar intimamente implicada com

\footnotetext{
3 As autoras escolheram denominar nesta pesquisa por "cirandeiros" os participantes da oficina, independentemente de serem crianças ou não.
} 


\section{SEMINÁRIO DE PESQUISA EM CIÊNCIAS HUMANAS - SEPECH \\ Humanidades, Estado e desafios didático-científicos \\ Londrina, 27 a 29 de julho de 2016}

métodos, objetivos e opções de valor, como base da ação planifica dos seres humanos, no sentido de relacionar a consciência do projeto proposto e o processo no qual se busca sua concretização.

Em um sentido também autônomo, o cirandeiro ao criar, implanta no mundo em que vive, uma perspectiva própria da realidade, o que indica, segundo Freire (1981), uma impaciência criativa frente um mundo até então pronto: "Não haveria criatividade sem a curiosidade que nos move e que nos põe pacientemente impacientes diante do mundo que não fizemos, acrescentando a ele algo que fazemos." (FREIRE, 1996, p. 18).

\subsection{Sobre o MH2 Música e hip hop}

O MH2 Música e hip hop, que a partir da consciência de Leandro Palmerah de que seu bairro é atravessado pelos abandonos do Estado anteriormente citados e não fadado à escassez por um simples acaso, constrói ferramentas para a transformação coletiva da realidade daquele bairro, instigando na população essa nova forma de relacionamento com a realidade. Um exemplo evidente deste processo de transformação da implicação do sujeito com sua realidade pode ser observado no decorrer dos saraus do projeto, conforme trecho do Diário de campo abaixo:

Durante o terceiro Sarau do Projeto MH2, Leandro Palmerah profere, em sua fala no palco, sobre questões do bairro entre as atividades artísticas e culturais que estavam lá acontecendo. Ele começa questionando o sol escaldante daquela tarde e leva a uma reflexão da falta de árvores plantadas no bairro, o qual mais se assemelha a um deserto de concreto. Até que começa a levar o questionamento sobre a falta de escola e espaços de convivência na região. Ele instiga os moradores a lutarem por qualidade de vida, e não se conformarem com os estigmas que a mídia propaga sobre aquela região, que os retrata apenas em ocorrências de violência extrema, esquecendo-os em todos os outros âmbitos. (Diário de campo, 20, set, 2015).

Sete meses posteriores à fala de Leandro Palmerah sobre a possibilidade de mudança da situação do bairro dependente da ação coletiva dos moradores, tornou-se concreta a ação coletiva para melhorias do bairro, veja-se registro do Diário de capo da pesquisadora:

Fui conversar com um dos moradores do bairro envolvido com o projeto. [...] ele logo me contou a novidade: na tarde anterior, ele e alguns moradores, plantaram árvores nas redondezas, sendo várias na calçada grafitada e outras frutíferas na rua de cima. Dizia ele: "Imagina: se ninguém arrancar elas, daqui alguns anos estarão "grandonas", imagina a rua cheia de pitanga!”. (Diário de campo, 24 abr, 2016).

A partir desse acontecimento é possível atribuir à transformação social a uma criação política dos moradores do bairro. Em decorrência dessas circunstancias e movimentos, é possível afirmar que Palmerah e seu projeto não são os agentes de transformação do bairro, mas o são todos os moradores e frequentadores deste. Leandro 


\section{SEMINÁRIO DE PESQUISA EM CIÊNCIAS HUMANAS - SEPECH \\ Humanidades, Estado e desafios didático-científicos \\ Londrina, 27 a 29 de julho de 2016}

Palmerah, no caso, trabalha com, jamais sobre, os indivíduos, a quem considera sujeitos e não objetos, incidências de sua ação.

Por essas razões Leandro Palmerah, a coordenadora Associação Ciranda da Cultura, ou as oficineiras da oficina Vozes do Ciranda, não poderiam ser identificados como "agentes da mudança", mas como parte desta, assim como todos que do trabalho social participam. (FREIRE P., 1981).

\subsection{Da centralidade das relações}

A partir das experiências na oficina Vozes do Ciranda, ou do projeto MH2 Música e Hip Hop, o que se pode concluir é que se existe alguma possibilidade de transformação da sociedade, no sentido da construção de uma realidade solidária e igualitária, isto deve ocorrer com a efetiva participação da população, bem como do envolvimento subjetivo dos indivíduos com os trabalhos sociais que se fizerem presentes.

A arte, portanto, é capaz de exprimir certa originalidade do indivíduo, de maneira que este se perceba potente, capaz e que, frente a situações postas como invariáveis, possa criar uma nova saída trilhando, de fato, um novo caminho subjetivo aos encontros. Coletivamente, a arte promove novas conexões, novos diálogos e o compartilhamento da beleza, dando forças à resistência e à luta política, de modo a construir uma prática própria das populações em situações de vulnerabilidade, tornando possível a construção de uma nova sociedade, pois, de acordo com Brandão (1985):

"Não é apenas em uma sociedade transformada que se cria uma nova cultura e um novo homem. É ao longo do processo coletivo de transformá-la, por meio do qual as classes populares se educam com a sua própria prática e consolidam o seu saber com o aporte da educação popular." (BRANDÃO, 1985. p,33)

Assim, quando em reencontro com a afirmação do título desta pesquisa, sobre um possível combate da violência por meio da arte, uma resposta pertinente seria a de que a arte atravessa os alcances da violência, de modo a restringir os efeitos desta. Não se trata, portanto de um combate direto, mas de uma nova proposta à existência dos sujeitos, a proposta de uma existência artística, frente à imposição de condições simbolicamente violentas à existência humana, como a falta ou precariedade de escolas ou postos de saúde.

O que se pode propor, em relação aos resultados obtidos nesta pesquisa, é de que os índices artísticos não devem ser comparados estatisticamente com os índices de violência, mas que iniciativas a fim de desenvolver a arte com os sujeitos, envolvendo sempre uma consciência crítica da sociedade, têm a potência de produzir formas de resistência e transformação. 


\section{REFERÊNCIAS}

BRASIL. Secretaria Nacional de Juventude. Mapa da Violência 2015. Disponível em: http://www.mapadaviolencia.org.br/pdf2015/mapaViolencia2015.pdf. Acesso em: 20 abr, 2016.

BRANDÃO, C. R. O que é educação. 1. ed. São Paulo: Brasiliense, 1985. Coleção Primeiro Passos.

LEÕN CEDEÑO, A. A. Psicología Comunitaria de lo Cotidiano: arte y acción psicosocial en Londrina (Brasil). Saarbrücken: Editorial Académica Española, 2012.

El trueque constructivo: buscando formas respetuosas de trabajo con prácticas contrahegemónicas. Fermentum, Revista Venezolana. de Sociología y Antropología, v.17 n.50 Mérida dic. $2007 . \quad$ Disponível http://www2.scielo.org.ve/scielo.php?script=sci arttext\&pid=S079830692007000300010\&lng=es\&nrm=i. Acesso em: 6 jul, 2015.

FREIRE, Paulo, Ação cultural para a liberdade. 5. ed. Rio de Janeiro, Paz e Terra. 1981.

Pedagogia da Autonomia: saberes necessários à pratica educativa. 25. ed. São Paulo: Paz e Terra, 1996.

FREIRE, Roberto \& BRITO, Fausto. Utopia e Paixão. 1. ed. Rio de Janeiro: Rocco, 1986.

HYPENESS. Para diminuir a violência escola demite seguranças e contrata professores de arte. Disponível em: http://www.hypeness.com.br/2013/09/pra-diminuirviolencia-escola-demite-segurancas-e-contrata-professores-de-arte/. Acesso em: 20 jun, 2015.

SILVA, Maria Nilza da. A cidade de Londrina: desigualdade, território e pertencimento étnico-racial. 2013.2 Disponível em: http://www.snh2013.anpuh.org/resources/anais/27/1364565704_ARQUIVO_Anpuh201 3-textofinal.pdf. Acesso em: 9 mai, 2016.

SPINK, P. O pesquisador conversador no cotidiano. Psicologia e Sociedade, Vol. 20, N.1, 2008. 